International Journal of Software Engineering \& Computer Systems (IJSECS)

ISSN: 2289-8522, Volume 2, pp. 120-132, February 2016

CUniversiti Malaysia Pahang

DOI: http://dx.doi.org/10.15282/ijsecs.2.2016.11.0022

\title{
THE NEED OF DASHBOARD IN SOCIAL RESEARCH NETWORK SITES FOR RESEARCHERS
}

\section{Siti Hawa Apandi, Ruzaini Abdullah Arshah}

\author{
Faculty of Computer Systems \& Software Engineering, Universiti Malaysia Pahang, \\ 26300 Gambang, Pahang, Malaysia \\ Email: sitihawa.apandi@gmail.com,ruzaini@ump.edu.my \\ Phone: +60139979560
}

\begin{abstract}
Nowadays, dashboard has been widely used by organizations to display information based on their objectives such as monitoring business performance or checking the current trend in the niche market. There is a need to investigate whether the researchers also need the dashboard in assisting their research works. There are some issues facing by researchers while using Social Research Network Sites (SRNS) since they could not noticed with information related to research field that they might be interested in because they are huge amounts of information in the SRNS. The inclusion of dashboard in the SRNS has to be explored to understand its relevancy in supporting the researchers work. We review previous works regarding dashboard usage to find the purposes of having dashboard and find researcher needs by reviewing researchers use scenario in the social networking sites. Then, we analyze whether the dashboard purposes can satisfy the researcher needs. From the analysis, we found out that the dashboard is a significant tool in assisting the researchers on: measuring their own research performance, monitoring research trends and alerting them with upcoming events.
\end{abstract}

Keywords: Dashboard; Social Research Network Sites; researchers; awareness.

\section{INTRODUCTION}

Many people have uses social media such as social networking sites as a platform for communication in their everyday life. The social networking sites rapidly flourished because it can connect people from anywhere at any time. Researchers as a part of the global community have also use the social networking sites for their research works, as well as getting connected with their peers. There are specialized social networking sites for the researchers known as Social Research Network Sites (SRNS). The researchers use the SRNS in order to fulfill their needs such as to find other researchers with similar interests or expertise, to keep in touch with their peers and to share information (Giglia, 2011; Li \& Gillet, 2013).

When the researchers use the SRNS, they are constantly generating information that single researchers might want to be noticed of but fail to do because they are huge amounts of information in the SRNS (Reinhardt, Kadam, et al., 2012) and it would overwhelm them (Reinhardt, Mletzko, Drachsler, \& Sloep, 2014). From this situation, we know that the researchers want to be noticed about the current information related to their research fields. This is similar with the awareness support in the context of Research Networks that want to make "actors more efficient and effective by making objects (such as people, paper, projects, events, research domains, writings, experts, social media artifacts and so on) and their relations to each other more noticeable for 
users" (Reinhardt, 2012; Reinhardt \& Mletzko, 2011). In order to cope with huge amount of information in the SRNS, the researchers need the awareness support to be embedded in their research practice (Reinhardt, Kadam, et al., 2012; Reinhardt, Mletzko, Sloep, \& Drachsler, 2012) because the awareness support improves the effectiveness of how information is spread in communities (Lövstrand, 1991) and positively influences social interactions taking place in those communities (Gross, Stary, \& Totter, 2005). The researchers also need metrics to measure their research performance. The metric is a type of performance measurement (Fitz-Gibbon, 1990) and it appear as a measurable number that usually used to evaluate success of the organizations or individuals. The researcher reputation is important so that they can be recognized by the other researchers in their research field. Therefore, the researchers will need a tool that can provide awareness support and to measure the researcher performance.

In this study, we investigate how the dashboard can be used to help satisfy the researcher needs in using SRNS. The remainder of this paper is structured as follows. In the next section, we discuss previous works on use of social networking by researchers, conceptualization of dashboard and dashboard for researchers. Methodology used in this study is then presented. This is followed with the discussion on the relevance of dashboard to researcher needs. Finally is the conclusion and future work of the study.

\section{PREVIOUS WORKS}

\section{Use of Social Networking Sites by Researchers}

The use of social networking sites for research has become essential parts of research practices (Cann, Dimitriou, \& Hooley, 2011; Reinhardt et al., 2014; Rowlands, Nicholas, Russell, Canty, \& Watkinson, 2011). This can be seen by many of today's researchers adopted more than one tool of social networking sites for research-related activities (Collins \& Hide, 2010; Gruzd, Staves, \& Wilk, 2012). The social networking sites being used by the researchers can be categorized into two which are general social networking sites and Social Research Network Sites (SRNS).

The general social networking sites have been defined as "a web-based service that allows individuals to: 1) construct a public or semi-private profile within a bounded system, 2) articulate a list of other users with whom they share a connection, and 3) view and traverse their list of connections and those made by others within the system" (Ellison, 2007). The general social networking sites are usually used for public purpose such as to keep in touch with other people, share information and also for entertainment and business use. It also can facilitate research works like exchanging research ideas, communicate and collaborate with the other researchers (Reinhardt et al., 2014). Facebook and Twitter are some examples of the general social networking sites most being used by the researchers (Gruzd \& Goertzen, 2013; Kumar \& Kumar, 2013; Madhusudhan, 2012). There are three basic functionalities in the general social networking sites which are functionality of identity and network management to present the user profile, functionality of information management to share information, and functionality of communication to interact with the other users. However, the researchers encounter a problem when they using the general social networking sites for their research work which they feel difficult to manage personal and professional identities (Gruzd \& Goertzen, 2013; Gruzd et al., 2012). They are also feel distracted by 
status updates appeared in news feeds as not every user use it to post status that related to the research work (Masud, Afrin, Choudhury, \& Ahmed, 2012).

As an alternative, the researchers use platforms that are specifically designed for research communities which are Social Research Network Sites (SRNS) (Bullinger, Hallerstede, Renken, Soeldner, \& Moeslein, 2010; Masud et al., 2012). The SRNS have been defined as a web-based service that allows individual researchers to: 1) construct a public or semi-public profile within a bounded system for identity purpose, 2) articulate a list of other researchers with whom they share a connection and communicate for communication purpose, 3) share information with other researchers within the system for information purpose and 4) collaborate with other researchers within the system for collaboration purpose (Bullinger et al., 2010). The SRNS can be categorized as one of the social networking sites based on the functionalities provided. There are four functionalities in the SRNS which are identity and network management, information management, communication and collaboration. The SRNS provide collaboration functionality, which is not included in the general social networking sites. These four functionalities in the SRNS has allows collaboration and interaction between the researchers. Research collaboration means any research activity that is carried out by multiple individuals overcoming institutional, disciplinary, and geographic boundaries (Masud et al., 2012). Most researchers collaborate with different reasons such as: share and expand knowledge, make new connections, increase possibility of getting funds, motivation, speedup the work or publish more (Alhoori \& Furuta, 2011). Further, the researchers can update and share information about their work and interests in the SRNS (Bullinger et al., 2010; Masud et al., 2012). Examples of the SRNS that mostly used by the researchers are Academia.edu, ResearchGate and Mendeley (Gruzd et al., 2012; Nentwich \& König, 2014; Reinhardt, Kadam, et al., 2012).

Based on the explanation above, we can differentiate between the general social networking sites and SRNS as shown in Table 1.

Table 1. Difference between general social networking sites and Social Research Network Sites.

\begin{tabular}{lll}
\hline & \multicolumn{1}{c}{ General social networking sites } & \multicolumn{1}{c}{$\begin{array}{c}\text { Social Research Network Sites } \\
\text { (SRNS) }\end{array}$} \\
\hline $\begin{array}{l}\text { Type of } \\
\text { users }\end{array}$ & $\begin{array}{l}\text { Wide range of users such as kids, } \\
\text { teenagers and adult people }\end{array}$ & $\begin{array}{l}\text { Users consist of people who are } \\
\text { involved in research works }\end{array}$ \\
\hline Purpose & $\begin{array}{l}\text { Used to keep in touch with other } \\
\text { people, socialize and entertainment }\end{array}$ & $\begin{array}{l}\text { Used to share research work and also } \\
\text { keep in touch and collaborate with } \\
\text { other researchers }\end{array}$ \\
\hline
\end{tabular}

It shows that the SRNS is more suitable platform to be used by the researchers for their research work, since the users consist of the researchers.

However, the SRNS still have issues in supporting research activities where the researchers still explore many sites in order for them to use different features provided and this could be time consuming for the researchers to manage those sites (Cann et al., 2011; Collins \& Hide, 2010; Masud et al., 2012; Nentwich \& König, 2014). The researchers want to be alerted on latest information in research field or looks for events on a specific topic but fail to do because they are huge amounts of information in the SRNS and it would overwhelm them (Masud et al., 2012; Reinhardt, Kadam, et al., 2012; Reinhardt et al., 2014). The researchers need the awareness support to be 
embedded in their research practice in order to handle the huge amount of information in the SRNS (Reinhardt, Kadam, et al., 2012; Reinhardt, Mletzko, et al., 2012). The awareness support can improves the effectiveness of how information is spread in communities (Lövstrand, 1991) and positively influences social interactions taking place in those communities (Gross et al., 2005). The dashboard can be used as a tool to provide awareness facility to the researchers because, from a user interface perspective, it is a facility in which users may find aggregated information about the system's current state, personal notifications, news and other important transactions (Reinhardt et al., 2014).

\section{Conceptualization of Dashboard}

We need to understand about dashboard in order to include dashboard as a tool to provide awareness to the researchers in the SRNS. The term dashboard is always associated with the dashboard used in vehicles (Mahendrawathi, Pranantha, \& Utomo, 2010; Pauwels et al., 2009; Yigitbasioglu \& Velcu, 2012). For example, a car dashboard provides us important information about status of the car likes amount of gas, speed and temperature. This information is important for the driver to make sure that the car is in good condition to be used for driving (Corp, 2004; Malik, 2005).

There are several definitions about the dashboard in the field of information management. Malik (2005) has define the dashboard as "a computer interface with charts, reports, visual indicators and alert mechanisms that are consolidated into dynamic and relevant information platform". Few (2006) state the dashboard as "a visual display of the most important information needed to achieve one or more objectives; consolidated and arranged on a single screen so the information can be monitored at a glance" (Few, 2006). Bose (2006) describe dashboard as "a software application that provides a single-screen display of relevant and critical business metrics and analytics to enable faster and more effective decision making".

Based on the dashboard definitions, we can identify criteria of dashboard as shown in Table 2.

Table 2. Criteria of dashboard.

\begin{tabular}{lllll}
\hline Author & \multicolumn{4}{c}{ Criteria of dashboard } \\
\cline { 2 - 5 } & $\begin{array}{l}\text { Display } \\
\text { information } \\
\text { needed to } \\
\text { achieve } \\
\text { specific } \\
\text { objectives }\end{array}$ & $\begin{array}{l}\text { Graphical } \\
\text { presentation }\end{array}$ & $\begin{array}{l}\text { Fits on a single } \\
\text { screen }\end{array}$ & $\begin{array}{l}\text { Provide alert } \\
\text { mechanisms }\end{array}$ \\
\hline $\begin{array}{l}\text { Malik } \\
(2005)\end{array}$ & & $/$ & & \\
\hline $\begin{array}{l}\text { Few } \\
(2006)\end{array}$ & $/$ & & $/$ & \\
\hline $\begin{array}{l}\text { Bose } \\
(2006)\end{array}$ & $/$ & $/$ & \multicolumn{1}{c}{} \\
\hline
\end{tabular}


The explanation about criteria of the dashboard is as follows:

i. Display information needed to achieve specific objectives

The right key metrics should be included in the dashboard to achieve specific objectives such as to indicate performance status (Few, 2006; Pauwels et al., 2009; West, 2012).

ii. Graphical presentation

The information should be presented in a form of visualizations such as gauges, charts, and tables, often color-coded for easy summarization (Bauer, 2004; Lehmann \& Reibstein, 2006). It is the best way to "present the information so that human eyes can take in quickly and human brains can easily extract the correct and most important meanings from it" (Few, 2006; Yigitbasioglu \& Velcu, 2012).

iii. Fits on a single screen

The information in the dashboard must fit on a single screen so that it is easy for the user to view the information at a glance (Few, 2006; Morton-Owens \& Hanson, 2012). If the information needs to be scroll, it has surpassed limitless of the dashboard (Mahendrawathi et al., 2010). The dashboard has provide drilldowns capabilities to display more detailed of the information (Bateman, Teevan, \& White, 2012; Mahendrawathi et al., 2010).

iv. Provide alert mechanisms

The alert mechanisms serve as a warning system when a key performance indicator (KPI) shows poor performance or an undesired trend. In order to attract user attention, the alert mechanisms accompanied by attention-capturing actions such as blinking (Malik, 2005).

We can conclude that the dashboard is a single screen interface with a graphical presentation that displays relevant information that needed to achieve particular objectives and accompanied with alert mechanisms.

\section{Dashboard for Researchers}

The study about dashboard should deserve ample research attention but it is hardly investigated by researchers (Maheshwari \& Janssen, 2013). There are limited studies concerning on the implementation of the dashboard for the researchers. Reinhardt et al. (2014), for example, provides an idea of a widget-based dashboard called AWESOME to support the researchers' awareness of their Research Networks, but has issue on addressing the participants' lack of knowledge on widget facility. There is also an application called PUSHPIN that helps the researchers to noticed of their connections to other researchers and publications that the researchers might be interested in by making recommendations (Reinhardt, Kadam, et al., 2012). With recommendations facility, users can noticed on the existence or linkage between objects likes researchers and publication papers that would have stayed hidden (Reinhardt et al., 2014). There are still more work can be done in dashboard for the researchers such as introducing metrics to measure the researcher performance in the dashboard. 


\section{METHODOLOGY}

The purpose of this study is to find significance of dashboard for the researchers. In order to do that, we analyze previous works regarding the researchers' reasons on using social networking sites in order to understand the researcher needs. Then, we have to investigate the dashboard usage to find its purposes. Further, we have to analyze the relevancy of the dashboard purposes with relation to the researcher needs. From the relationship relevancy, we can provide the justification on the significance of the dashboard for the researchers needs. Figure 1 shows the methodology used in this study.

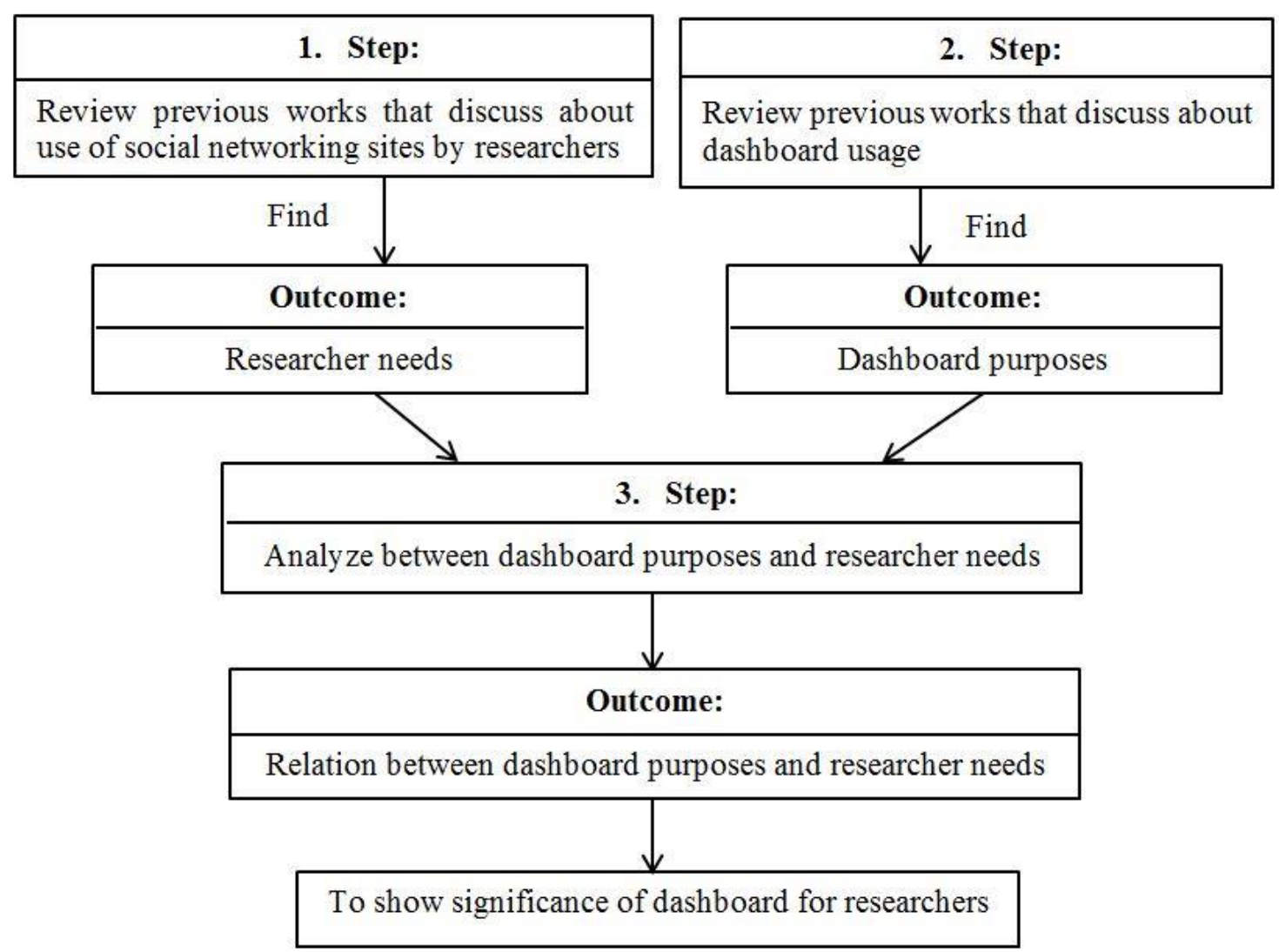

Figure 1. Methodology used in this study.

\section{RELEVANCE OF DASHBOARD TO RESEARCHER NEEDS}

We used most widely academic search engine, Google Scholar (Osborne, Motta, \& Mulholland, 2013) to find previous works that discuss about the researchers use of social networking sites and also the usage of the dashboard. The keywords that we used to find the previous works were "social networking sites", "researchers", "dashboard", "performance measurement" and "awareness". We filtered the articles that relevance to our study. This approach of review previous works also had been used in (Yigitbasioglu $\&$ Velcu, 2012). We used a concept matrix to extract important points from the previous works (Webster \& Watson, 2002).

We review previous works regarding the use of social networking sites by the researchers in order to understand the researcher needs. Firstly, most of the researchers use the social networking sites as a platform to publicize their research outputs (Gruzd 
et al., 2012; Nentwich \& König, 2014; Rowlands et al., 2011; Thelwall \& Kousha, 2014). They want their publication papers to be read and cite by the other researchers. Metrics are needed to measure their research impact such as number of citation and download of the publication paper. A performance of the researcher can be measured (RN1) (Giglia, 2011; Li \& Gillet, 2013; Masud et al., 2012; Nentwich \& König, 2014; Osborne et al., 2013; Rohani \& Ow, 2011; Thelwall \& Kousha, 2014) so that they can be recognized by the other researchers. The social networking sites have ability to support the researcher needs to find information other researchers (RN2) and publication papers (RN3) (Chakraborty, 2012; Giglia, 2011; Gruzd et al., 2012; Masud et al., 2012) but they encounter a problem where the researchers could not noticed about these information since there are huge amounts of information in the social networking sites (Reinhardt, Kadam, et al., 2012). Next, the researchers also want to be alerts on upcoming events likes seminar and conferences (RN4) (Chakraborty, 2012; Gruzd et al., 2012; Madhusudhan, 2012; Masud et al., 2012) to enable they plan to the event they interested to submit the publication paper. Lastly, there is a need to monitor research trends in order to know which research fields are growing and shrinking (RN5) (Masud et al., 2012; Osborne et al., 2013) as the social networking sites involve all researchers from diverse research fields. We have summarize five points regarding the researcher needs which are measure performance of researcher (RN1), to know information about the other researchers (RN2) and publication papers (RN3), alerts on upcoming events likes seminar and conferences (RN4) and to monitor research trends (RN5) as presented in Table 3. 
Table 3. Researcher needs.

\begin{tabular}{|c|c|c|c|c|c|}
\hline \multirow[t]{2}{*}{ Author } & \multicolumn{5}{|c|}{ Researcher needs } \\
\hline & $\begin{array}{l}\text { Measure } \\
\text { performance } \\
\text { of researcher } \\
\text { (RN1) }\end{array}$ & $\begin{array}{l}\text { Information } \\
\text { about other } \\
\text { researchers } \\
\text { (RN2) }\end{array}$ & $\begin{array}{l}\text { Information } \\
\text { about } \\
\text { publication } \\
\text { papers } \\
\text { (RN3) }\end{array}$ & $\begin{array}{l}\text { Alerts on } \\
\text { upcoming } \\
\text { events likes } \\
\text { seminar and } \\
\text { conferences } \\
\text { (RN4) }\end{array}$ & $\begin{array}{l}\text { Monitor } \\
\text { research } \\
\text { trends } \\
\text { (RN5) }\end{array}$ \\
\hline Giglia (2011) & I & I & I & & \\
\hline $\begin{array}{l}\text { Rohani and } \\
\text { Ow (2011) }\end{array}$ & I & & & & \\
\hline $\begin{array}{l}\text { Chakraborty } \\
\text { (2012) }\end{array}$ & & / & / & / & \\
\hline $\begin{array}{l}\text { Gruzd et al. } \\
\text { (2012) }\end{array}$ & & I & I & I & \\
\hline $\begin{array}{l}\text { Madhusudhan } \\
\text { (2012) }\end{array}$ & & & & I & \\
\hline $\begin{array}{l}\text { Masud et al. } \\
\text { (2012) }\end{array}$ & I & I & I & I & / \\
\hline $\begin{array}{l}\text { Li and Gillet } \\
\text { (2013) }\end{array}$ & / & & & & \\
\hline $\begin{array}{l}\text { Osborne et al. } \\
\text { (2013) }\end{array}$ & I & & & & / \\
\hline $\begin{array}{l}\text { Nentwich and } \\
\text { König (2014) }\end{array}$ & / & & & & \\
\hline $\begin{array}{l}\text { Thelwall and } \\
\text { Kousha (2014) }\end{array}$ & I & & & & \\
\hline
\end{tabular}

We also review previous works regarding the dashboard usage to find out the dashboard purpose. Firstly, most previous works state that the dashboard been used for performance measurement (DP1) (Bose, 2006; Mahendrawathi et al., 2010; Maheshwari \& Janssen, 2013; Morton-Owens \& Hanson, 2012; Pauwels et al., 2009; Phippen, Sheppard, \& Furnell, 2004; Yigitbasioglu \& Velcu, 2012). For example, Phippen et al. (2004) describes the dashboard used to report monthly and weekly performance of multinational airline company's website such as visits, visitors, registrations and visits to bookings information. Secondly, the dashboard used to guide decision making (DP2) (Bose, 2006; Mahendrawathi et al., 2010; Morton-Owens \& Hanson, 2012; Pauwels et al., 2009; Yigitbasioglu \& Velcu, 2012). For example, manager use dashboard in marketing to guide on decisions, such as, promotion activities and sales force allocation (Pauwels et al., 2009). Thirdly, the dashboard has been used to provide awareness support (DP3) (Bose, 2006; Reinhardt, Kadam, et al., 2012; Reinhardt et al., 2014; Treude \& Storey, 2010). The awareness means "an understanding of the activities of others, which provides a context for your own activity" (Dourish \& Bellotti, 1992). In (Reinhardt, Kadam, et al., 2012; Reinhardt et al., 2014), the dashboard had been implemented for the researchers to provide the awareness support in the context of Research Networks that want to make the researchers noticed information about the other researchers and publication papers that they might be interested (Reinhardt, 2012; Reinhardt \& Mletzko, 2011). While in (Treude \& Storey, 2010), the dashboard used by 
software development teams to provide awareness for project status. Bose (2006) state alert messages can be used to make the user aware of the information needed. Lastly, the dashboard also can be used to monitor trend over time (DP4) (Maheshwari \& Janssen, 2013; Morton-Owens \& Hanson, 2012; Phippen et al., 2004). By comparing current and past information, the dashboard can identify what trending up or down. Based on previous works of the dashboard usage, we have identified four points regarding the dashboard purposes; namely performance measurement (DP1), guide decision making (DP2), provide awareness support (DP3) and monitor trend over period of time (DP4) as presented in Table 4.

Table 4. Dashboard purposes.

\begin{tabular}{|c|c|c|c|c|}
\hline \multirow[t]{2}{*}{ Author } & \multicolumn{4}{|c|}{ Dashboard purposes } \\
\hline & $\begin{array}{l}\text { Performance } \\
\text { measurement } \\
\text { (DP1) }\end{array}$ & $\begin{array}{l}\text { Guide } \\
\text { decision } \\
\text { making (DP2) }\end{array}$ & $\begin{array}{l}\text { Provide } \\
\text { awareness } \\
\text { support (DP3) }\end{array}$ & $\begin{array}{l}\text { Monitor trend } \\
\text { over period of } \\
\text { time (DP4) }\end{array}$ \\
\hline $\begin{array}{l}\text { Phippen et al. } \\
\text { (2004) }\end{array}$ & I & & & / \\
\hline Bose (2006) & 1 & 1 & 1 & \\
\hline $\begin{array}{l}\text { Pauwels et al. } \\
\text { (2009) }\end{array}$ & I & I & & \\
\hline $\begin{array}{l}\text { Mahendrawathi } \\
\text { et al. (2010) }\end{array}$ & I & I & & \\
\hline $\begin{array}{l}\text { Treude and } \\
\text { Storey (2010) }\end{array}$ & & & I & \\
\hline $\begin{array}{l}\text { Morton-Owens } \\
\text { and Hanson } \\
(2012)\end{array}$ & I & / & & I \\
\hline $\begin{array}{l}\text { Reinhardt et al. } \\
\text { (2014) }\end{array}$ & & & I & \\
\hline $\begin{array}{l}\text { Reinhardt, } \\
\text { Kadam, et al. } \\
(2012)\end{array}$ & & & I & \\
\hline $\begin{array}{l}\text { Yigitbasioglu and } \\
\text { Velcu (2012) }\end{array}$ & I & I & & \\
\hline $\begin{array}{l}\text { Maheshwari and } \\
\text { Janssen (2013) }\end{array}$ & I & & & I \\
\hline
\end{tabular}

The purposes of the dashboard (DP1-DP4) are then analyzed to seek whether these purposes can satisfy the needs of researcher (RN1-RN5) in their research works. From the analysis, we can see the relevance of the dashboard to be used by the researchers to cater their needs.

Every day, each research field gets deeper with increasing number of publication papers. Thus, a research trends can be generated (RN5) such as by making comparison number of publication papers in various research fields versus years. From that, we can see which research fields are growing and shrinking. The dashboard can be used to monitor trend over period of time (DP4).

The information about the researcher and publication are related with one another. For instance, impact factor of the publication paper can influence the researcher 
reputation ( $\mathrm{Li} \&$ Gillet, 2013). The impact factor can be example of the metric to measure the researcher performance which might help them to know their ranking in the research community. As stated by Rohani and Ow (2011), "ranking mechanism can create an enthusiasm for users to increase their rank and enhance their position in their university or colleges". The dashboard can be used to measure performance of researcher (RN1) as the dashboard has been used by the company to measure their business performance (DP1).

Besides, the researchers want to be alerts on upcoming events likes seminar and conferences on a specific topic (RN4). Thus, the researchers can submit their publication paper to the event that related to their research interests (Chakraborty, 2012; Tang et al., 2008). The dashboard has ability to provide awareness support (DP3) (Reinhardt, Kadam, et al., 2012; Reinhardt et al., 2014; Treude \& Storey, 2010) to make the researchers noticed information about the other researchers, publication papers and events related to their research interest.

Table 5 shows the relationship between the need of researchers with the dashboard purposes. From here, we can see relevance of the dashboard purposes to cater the researcher needs.

Table 5. Relationship between dashboard purposes and researcher needs.

\begin{tabular}{ll}
\hline \multicolumn{1}{c}{ Dashboard purposes } & \multicolumn{1}{c}{ Researcher needs } \\
\hline Monitor trend over period of time (DP4) & Monitor research trends (RN5) \\
\hline Performance measurement (DP1) & Measure performance of researcher (RN1) \\
\hline Provide awareness support (DP3) & $\begin{array}{l}\text { Alerts on upcoming events likes seminar } \\
\text { and conferences (RN4) }\end{array}$ \\
\hline
\end{tabular}

Based on the analysis, the dashboard is identified as a significant tool in assisting the researcher needs on: 1) measuring their own research performance, 2) monitoring research trends and 3) alerting them with upcoming events.

\section{CONCLUSION AND FUTURE WORK}

The main contribution of this paper is to show significance of dashboard for researchers based on a relation between the dashboard purpose and the researcher needs. The dashboard has been identified to help the researchers to measure the researcher performance, to monitor research trends and alerts on upcoming events. Future work will be to identify dashboard items by reviewing features in the existing social networking sites. The dashboard items identification will be selected based on suitability to support the researcher needs on the dashboard. With these dashboard items, a proposed model of researchers' dashboard in SRNS can be established.

\section{REFERENCES}

Alhoori, H., \& Furuta, R. (2011). Understanding the dynamic scholarly research needs and behavior as applied to social reference management. Research and Advanced Technology for Digital Libraries, 169-178.

Bateman, S., Teevan, J., \& White, R. W. (2012). The search dashboard: How reflection and comparison impact search behavior. Proceedings of the SIGCHI Conference on Human Factors in Computing Systems, 1785-1794. 
Bauer, K. (2004). The CPM dashboard: The visuals. Information Management, 14(5), 41.

Bose, R. (2006). Understanding management data systems for enterprise performance management. Industrial Management \& Data Systems, 106(1), 43-59.

Bullinger, A. C., Hallerstede, S. H., Renken, U., Soeldner, J.-H., \& Moeslein, K. M. (2010). Towards research collaboration - A taxonomy of Social Research Network Sites. AMCIS 2010 Proceedings, 1-9.

Cann, A., Dimitriou, K., \& Hooley, T. (2011). Social media: A guide for researchers. London: Research Information Network.

Chakraborty, N. (2012). Activities and reasons for using social networking sites by research scholars in NEHU: A study on Facebook and ResearchGate. 8th Convention PLANNER-2012, 19-27.

Collins, E., \& Hide, B. (2010). Use and relevance of Web 2.0 resources for researchers. 14th International Conference on Electronic Publishing, 271-289.

Corp, N. (2004). Dashboard development and deployment: A methodology for success.

Dourish, P., \& Bellotti, V. (1992). Awareness and coordination in shared workspaces. Proceedings of the 1992 ACM conference on Computer-supported cooperative work, 107-114.

Ellison, N. B. (2007). Social network sites: Definition, history, and scholarship. Journal of Computer-Mediated Communication, 13(1), 210-230.

Few, S. (2006). Information dashboard design: O'Reilly.

Fitz-Gibbon, C. T. (1990). Performance indicators (Vol. 2): Multilingual Matters.

Giglia, E. (2011). Academic social networks: It's time to change the way we do research. European journal of physical and rehabilitation medicine, 47(2), 345349.

Gross, T., Stary, C., \& Totter, A. (2005). User-centered awareness in computersupported cooperative work-systems: Structured embedding of findings from social sciences. International Journal of Human-Computer Interaction, 18(3), 323-360.

Gruzd, A., \& Goertzen, M. (2013). Wired Academia: Why social science scholars are using Social Media. 2013 46th Hawaii International Conference on System Sciences (HICSS), 3332-3341.

Gruzd, A., Staves, K., \& Wilk, A. (2012). Connected scholars: Examining the role of social media in research practices of faculty using the UTAUT model. Computers in Human Behavior, 28(6), 2340-2350.

Kumar, A., \& Kumar, R. (2013). Use of Social Networking Sites (SNSs): A study of Maharishi Dayanand University, Rohtak, India. Library Philosophy and Practice (e-journal).

Lehmann, D. R., \& Reibstein, D. J. (2006). Marketing metrics and financial performance: Marketing Science Inst.

Li, N., \& Gillet, D. (2013). Identifying influential scholars in academic social media platforms. Proceedings of the 2013 IEEE/ACM International Conference on Advances in Social Networks Analysis and Mining, 608-614.

Lövstrand, L. (1991). Being selectively aware with the khronika system. Proceedings of the Second European Conference on Computer-Supported Cooperative Work, 265-277.

Madhusudhan, M. (2012). Use of social networking sites by research scholars of the University of Delhi: A study. The International Information \& Library Review, 44(2), 100-113. 
Mahendrawathi, E., Pranantha, D., \& Utomo, J. D. (2010). Development of dashboard for hospital logistics management. 2010 IEEE Conference on Open Systems (ICOS), 86-90.

Maheshwari, D., \& Janssen, M. (2013). Measurement and benchmarking foundations: Providing support to organizations in their development and growth using dashboards. Government Information Quarterly, 30, S83-S93.

Malik, S. (2005). Enterprise dashboards: Design and best practices for IT: John Wiley $\&$ Sons.

Masud, S., Afrin, M., Choudhury, F. M., \& Ahmed, S. I. (2012). VizResearch: Linking the knowledge of people and the people with knowledge. Procedia Computer Science, 9, 1416-1425.

Morton-Owens, E. G., \& Hanson, K. L. (2012). Trends at a glance: A management dashboard of library statistics. Information Technology and Libraries, 31(3), 3651.

Nentwich, M., \& König, R. (2014). Academia goes Facebook? The potential of social network sites in the scholarly realm Opening Science (pp. 107-124): Springer International Publishing.

Osborne, F., Motta, E., \& Mulholland, P. (2013). Exploring scholarly data with rexplore The Semantic Web-ISWC 2013 (pp. 460-477): Springer.

Pauwels, K., Ambler, T., Clark, B. H., LaPointe, P., Reibstein, D., Skiera, B., . . . Wiesel, T. (2009). Dashboards as a service: Why, what, how, and what research is needed? Journal of Service Research, 12(2), 175-189.

Phippen, A., Sheppard, L., \& Furnell, S. (2004). A practical evaluation of Web analytics. Internet Research, 14(4), 284-293.

Reinhardt, W. (2012). Awareness support for knowledge workers in research networks. (Ph.D. Thesis), Open University in the Netherlands (CELSTEC), Heerlen, The Netherlands.

Reinhardt, W., Kadam, P., Varlemann, T., Surve, J., Ahmad, M. I., \& Magenheim, J. (2012). Supporting scholarly awareness and researchers' social interactions using PUSHPIN. Proceedings of the 2nd workshop on awareness and reflection in technology-enhanced learning, CEUR Workshop Proceedings, 31-46.

Reinhardt, W., \& Mletzko, C. (2011). Awareness in learning networks. Proceedings of the PLE Conference 2011, 12-20.

Reinhardt, W., Mletzko, C., Drachsler, H., \& Sloep, P. B. (2014). Design and evaluation of a widget-based dashboard for awareness support in Research Networks. Interactive Learning Environments, 22(5), 594-613.

Reinhardt, W., Mletzko, C., Sloep, P. B., \& Drachsler, H. (2012). Understanding the meaning of awareness in Research Networks. Proceedings of the 2nd Workshop on Awareness and Reflection in Technology Enhanced Learning, Saarbrücken, Germany, 13-30.

Rohani, V. A., \& Ow, S. H. (2011). Eliciting essential requirements for social networks in academic environments. 2011 IEEE Symposium on Computers \& Informatics, 171-176.

Rowlands, I., Nicholas, D., Russell, B., Canty, N., \& Watkinson, A. (2011). Social media use in the research workflow. Learned Publishing, 24(3), 183-195.

Tang, J., Zhang, J., Yao, L., Li, J., Zhang, L., \& Su, Z. (2008). Arnetminer: Extraction and mining of academic social networks. Proceedings of the 14th ACM SIGKDD international conference on knowledge discovery and data mining, 990-998. 
Thelwall, M., \& Kousha, K. (2014). Academia.edu: Social Network or Academic Network? Journal of the Association for Information Science and Technology, 65(4), 721-731.

Treude, C., \& Storey, M. (2010). Awareness 2.0: Staying aware of projects, developers and tasks using dashboards and feeds. 2010 ACM/IEEE 32nd International Conference on Software Engineering, 365-374.

Webster, J., \& Watson, R. T. (2002). Analyzing the past to prepare for the future: Writing a literature review. Management Information Systems Quarterly, 26(2), 3.

West, D. M. (2012). Big data for education: Data mining, data analytics, and web dashboards. Governance Studies at Brookings.

Yigitbasioglu, O. M., \& Velcu, O. (2012). A review of dashboards in performance management: Implications for design and research. International Journal of Accounting Information Systems, 13(1), 41-59. 